Cahiers $d u$ MONDE RUSSE

\section{Cahiers du monde russe}

Russie - Empire russe - Union soviétique et États indépendants

$60 / 4 \mid 2019$

Varia

\title{
Malte ROLF, Soviet Mass Festivals, 1917-1991
}

\section{Sylvain Dufraisse}

\section{OpenEdition \\ Journals}

Édition électronique

URL : https://journals.openedition.org/monderusse/11531

DOI : 10.4000/monderusse. 11531

ISSN : $1777-5388$

Éditeur

Éditions de l'EHESS

Édition imprimée

Date de publication : 1 octobre 2019

Pagination : 858-861

ISBN : 978-2-7132-2797-4

ISSN : $1252-6576$

\section{Référence électronique}

Sylvain Dufraisse, "Malte ROLF, Soviet Mass Festivals, 1917-1991 ", Cahiers du monde russe [En ligne], 60/4 | 2019, mis en ligne le 01 octobre 2019, consulté le 07 janvier 2023. URL : http://

journals.openedition.org/monderusse/11531; DOI : https://doi.org/10.4000/monderusse.11531 


\section{Malte ROLF}

\section{Soviet Mass Festivals, 1917-1991}

Pittsburgh : Pittsburgh University Press, 2013, 324 p.

L'invention d'une nouvelle culture festive dans la Russie bolchevique, puis en Union soviétique, et l'institutionnalisation de rites et de traditions nouvelles est un phénomène désormais bien connu et arpenté. L'ouvrage de Malte Rolf, publié en allemand en 2006, traduit en anglais en 2013, éclaire un aspect de l'histoire des politiques symboliques. Il se propose d'étudier comment les fêtes politiques ( $1^{\text {er }}$ mai, 8 mars, anniversaire de la révolution d'Octobre...) en Union soviétique sont devenues un moyen de communication privilégié entre l'État, le parti et la société et ont donné lieu à des festivités de masse. L'ampleur chronologique ambitieuse, promise dans le titre, se révèle finalement plus restreinte. L'ouvrage se concentre principalement sur les années 1917-1941 et aborde plus rapidement le second vingtième siècle. Il vise à comprendre pourquoi le régime soviétique s'est impliqué dans la création d'un nouveau calendrier de jours de fête, marqué par de pompeuses célébrations et ce que ses dirigeants attendaient de ces chorégraphies, regroupant des foules nombreuses, nécessitant une organisation millimétrée.

Le travail de M. Rolf s'inscrit dans une perspective d'histoire culturelle du politique. Il examine les formes des manifestations, les politiques symboliques, les liens avec les célébrations préexistantes et l'hybridation entre pratiques d'« ancien régime » et pratiques soviétiques. Il se révèle tout aussi riche pour appréhender l'histoire politique et sociale de la culture en Union soviétique. L'ouvrage est attentif aux individus qui produisent les politiques culturelles et aux formes d'action publique tant locales que nationales. L'auteur tente ponctuellement de saisir le rôle de ces fêtes dans la constitution d'émotions collectives et dans le processus de subjectivation. M. Rolf s'est appuyé sur des sources volumineuses issues des archives centrales moscovites et locales, des régions de Voronež et Novosibirsk. 
Il a ainsi souhaité comprendre la diffusion et l'application de politiques à l'échelle régionale et la part de Moscou dans la gestion des fêtes régionales et locales. Cet aspect du livre est un de ses points forts. Il permet ainsi de mieux comprendre les relations entre les différentes strates d'organisateurs de festivités. L'auteur s'est aussi appuyé sur de nombreuses sources iconographiques (peintures, affiches, photographies), dont certaines ont été reproduites dans le livre. Les photographies de parades et de manifestations réalisées dans la région de Novosibirsk donnent à voir des cortèges et des rassemblements moins structurés que les images habituelles d'Ivan Šagin ou d'Aleksander Rodčenko, qui imprègnent les représentations collectives occidentales des fêtes soviétiques des années 1930. L'auteur, enfin, s'est appuyé sur les écrits théoriques et didactiques des penseurs et des organisateurs de célébrations pour appréhender les débats ayant traversé ces milieux et les visions qui avaient fini par primer. L'usage de quelques journaux intimes tente de cerner comment les individus furent marqués par ces commémorations et comment, en retour, ces fêtes ont pu participer à leur construction en tant que citoyens soviétiques, sans être résolument convaincant.

L'ouvrage est composé de six chapitres d'inégale longueur. Le premier, assez court, se propose de revenir sur les célébrations qui existaient durant la période impériale et témoignent de l'existence contiguë de jours fériés et de fêtes : cérémonies impériales, liées à l'histoire de la Russie, processions religieuses, fêtes paysannes, célébrations liées aux milieux bourgeois ou aristocratiques, aux groupes nationaux ou au mouvement ouvrier. L'auteur montre alors que la période 1903-1913 rompt avec les habitudes traditionnelles impériales en accordant plus de place dans la dramaturgie des cérémonies aux nouveaux médias de masse (films, objets publicitaires). Le deuxième chapitre aborde les manières dont furent pensées les commémorations qu'imposent les bolcheviks au pouvoir. Établissant un nouveau calendrier des fêtes et des emblèmes neufs, ils cherchent par les célébrations à marquer une rupture entre l'ancien et le nouveau régime et à légitimer leur pouvoir. Comme d'autres milieux ou pratiques, la rupture bolchevique donne lieu à de nombreux débats théoriques sur le sens politique de la célébration, sur ses formes et sur ses objectifs sociaux. En parallèle, la multiplication des commémorations contribue à légitimer un groupe d'experts des célébrations et de leur organisation, comme Orest Cehnovicer ou Nikolaj Podvojskij, qui peuplent les commissions à l'échelle pansoviétique ou régionale. Localement, les nouvelles fêtes promues et les organisateurs s'appuient sur des cercles d'amateurs mais ils font face à la persistance des pratiques religieuses ou paysannes et surtout au manque de moyens pour les préparer.

À la fin des années 1920, les célébrations soviétiques changent de nature. Elles ne doivent plus être de seuls moyens d'éducation. Elles sont censées assurer le divertissement des masses et, sous la forme d'un loisir actif, permettre l'augmentation des performances de production et l'essor de l'attachement patriotique. Le gigantisme, la compacité des foules, le dénombrement des participants permettent de donner à voir la supériorité du régime soviétique et l'adhésion des foules à ces nouveaux divertissements collectifs. Comme les actes de planification urbaine ou les projets 
d'ingénierie des paysages, les fêtes manifestent tout autant le pouvoir croissant de l'État sur l'espace, à moindre coût. Ponctuellement, elles participent à redéfinir les espaces urbains et à les marquer de son emprise, par les décorations ou les constructions réalisées. Les fêtes et commémorations suivent un plan central, déterminé par des experts. Parallèlement, se développent des départements de recherche et des instituts de formation spécifiques. La communauté des experts en commémoration cherche ainsi à professionnaliser l'organisation des célébrations et à en conserver le monopole. L'ouvrage s'attache ensuite à analyser les manifestations commémoratives dans leurs dimensions performatives (chapitre 3). Les célébrations mettent en scène le futur envisagé, comme elles sont un moyen de faire correspondre le présent à cette vision de l'avenir. Elles reflètent tout autant les hiérarchies spatiales, ethniques et sociales et permettent aux autorités d'assigner les identités, comme aux individus d'identifier leur place dans le collectif. Le très riche chapitre 4 étudie comment le temps de la fête et de son organisation est un moment et un espace privilégié de communication. Les autorités locales de Voronež et Novosibirsk adaptent les ordres centraux. L'auteur saisit la manière dont les commémorations sont le produit de négociations entre autorités locales et centrales. Il apporte des éléments intéressants sur les difficultés à acclimater localement dans les villes des régions de Novosibirsk et de Voronež la dramaturgie imposée par Moscou, tant les pénuries sont nombreuses, tant les budgets consacrés aux commémorations sont faibles et tant les populations sont rétives à participer ou trop indisciplinées dans les cortèges. Malte Rolf, lorsqu'il s'intéresse aux fêtes dans les villages, montre la faible pénétration des nouvelles cultures festives dans les campagnes et la persistance des fêtes religieuses et des coutumes païennes. Sa lecture des archives locales a néanmoins permis de dévoiler des formes d'appropriation de ces fêtes et du calendrier : les autorités locales, comme les collectifs de citoyens, profitent de ces célébrations pour demander des subsides supplémentaires ou la rénovation de leurs dortoirs ou de leurs baraquements! L'organisation des fêtes, comme espaces de contact entre les individus et les dirigeants et de performance du régime, est un moment approprié pour articuler les demandes des citoyens soviétiques aux exigences du régime et faire qu'elles soient entendues.

Les deux derniers chapitres sont plus brefs et moins fouillés. Le chapitre 5 compare les célébrations politiques soviétiques des années 1930 aux fêtes nazies et fascistes et à celles de la république de Weimar et des États-Unis, sans être très convaincant. Le chapitre 6, de manière assez allusive, décrit les évolutions des fêtes en URSS de 1941 à 1991, en insistant sur le recentrement progressif des célébrations sur des collectifs amicaux ou familiaux et sur l'adaptation dans les espaces nouvellement soviétisés et dans les démocraties populaires du calendrier et des formes soviétiques. Enfin, il montre comment, marginalisées à la chute de l'URSS, les fêtes inventées par le régime soviétique persistent dans la Russie actuelle et connaissent une ferveur renouvelée.

Ce volume, touffu et parfois fastidieux à lire, éclaire toutefois un aspect important de la vie culturelle soviétique, les célébrations collectives. Il documente de manière précise les manières dont se constituaient en URSS ces politiques culturelles, 
retraçant les interactions entre les différents centres, nationaux et locaux, avec une partie de leur territoire.

Sylvain Dufraisse

Université de Nantes 